\title{
Restraint Stress Fails to Render C57BL/6 Mice Susceptible to Theiler's Virus-Induced Demyelination
}

\author{
Andrew J. Steelman ${ }^{a}$ Eric Alford ${ }^{a}$ Colin R. Young ${ }^{a}$ Thomas H. Welsh ${ }^{c}$ \\ Mary W. Meagher ${ }^{d} \quad$ C. Jane R. Welsh ${ }^{a, b}$ \\ Departments of ${ }^{a}$ Veterinary Integrative Biosciences and ${ }^{b}$ Veterinary Pathobiology, College of Veterinary Medicine \\ and Biomedical Sciences, 'Department of Animal Science, College of Agriculture, and ${ }^{\mathrm{d} D e p a r t m e n t}$ of Psychology, \\ College of Liberal Arts, Texas A\&M University, College Station, Tex., USA
}

\section{Key Words}

Multiple sclerosis · Stress • Susceptibility · Theiler's virus •

Viral persistence

\begin{abstract}
Objectives: Multiple sclerosis is a degenerative disease of the CNS with a pathology consistent with immunological mediation. Although its cause is unknown, multiple factors are thought to influence both the onset and exacerbation of the disease, including both genetic background as well as environmental factors. Methods: We are interested in the effect of psychological stress on the onset and exacerbation of Theiler's virus-induced demyelinating disease (TVID), a murine model of MS in which viral persistence facilitates demyelination. In the current study, we determined whether chronic restraint stress (RS)-induced immunosuppression could result in the establishment of a persistent CNS infection in the normally TVID-resistant C57BL/6 mouse strain, resulting in demyelination. Results: Our data indicated that RS repeated over the course of 7 days was not sufficient to cause decreases in virus-specific adaptive immunity, and did not significantly alter CNS viral levels. Furthermore, chronic repeated RS lasting until 4 weeks after infection altered neither the development of virus-specific IgG nor motor function determined by Rotarod analysis. In addition, histolog-
\end{abstract}

ical analysis of the CNS of stressed mice indicated no inflammation or demyelination on day 193 after infection. Conclusion: These results suggest that stress alone is not sufficient to overcome genetic resistance to TVID in the C57BL/6 mouse strain.

Copyright $\odot 2009$ S. Karger AG, Basel

\section{Introduction}

Multiple sclerosis (MS) is a chronic idiopathic demyelinating and neurodegenerative disease of the central nervous system. As such, both the onset and exacerbation of MS are thought to be influenced by multiple factors, including infectious agents, genetic composition and environment [1]. Evidence suggesting an infectious agent in the etiology of MS includes the association of multiple viral infections with MS [2], the precedence of relapses by infection [3, 4] and epidemiological studies demonstrating MS outbreaks in areas with no previous history of the disease, most notable in the Faroe Islands [5]. Additionally, human viral infections are known to cause demyelination both through direct lysis of oligodendrocytes, as occurs in progressive multifocal leukoencephalopathy brought on by polyoma JC virus infection, and indirectly, as is the case in post-infectious (PI) acute disseminated

Dr. C. Jane Welsh

Department of Veterinary Integrative Biosciences

College of Veterinary Medicine and Biomedical Sciences, Texas A\&M University College Station, TX 77843-4458 (USA)

Tel. +1 979862 4974, Fax +1 979847 8981, E-Mail jwelsh@cvm.tamu.edu 
encephalomyelitis initiated by vaccination or infection [6] and subacute sclerosing panencephalitis caused by measles virus infection [7]. In addition, virus-induced demyelination is demonstrable in animals. For instance, infection of Icelandic sheep with visna virus [8]; dogs with canine distemper virus [9], and mice with Semliki forest virus, the JHM strain of murine hepatitis virus, or Theiler's murine encephalomyelitis virus (TMEV) [1012] - all induce demyelinating diseases of the CNS that pathologically resemble human MS.

Aside from evidence supporting an infectious trigger for MS onset and exacerbation, genetic predisposition to the disease is also likely to play a role in the pathogenesis of MS. This is illustrated by studies conducted on twins that demonstrate an approximate $30 \%$ concordance rate among monozygotic twins but only a $3-5 \%$ rate among dizygotic twins [13-16]. Indeed, multiple loci representing nearly every chromosome have been associated with MS [17]. However, to date, the strongest and most reproducible genetic link, accounting for an estimated $17-60 \%$ of the genetic association with MS, is the HLA gene HLA-DRB1 [1, 18].

Other environmental stimuli, such as psychological stressors, have also been implicated in the pathogenesis of MS. Interestingly, stress has been repeatedly associated with both onset [19-21] and exacerbation [22-24] of the disease, although the mechanism(s) behind these effects of stress on MS are currently poorly understood.

TMEV is a member of the Picornaviridae family. TMEV infection of mice provides an excellent model to study human MS because it is endemic in mice although, in nature, it rarely causes demyelinating disease [25]. Moreover, the development of Theiler's virus-induced demyelinating disease (TVID), the chronic progressive immune-mediated demyelinating and neurodegenerative disease, has been shown to depend on viral persistence within the CNS. Both $\mathrm{H}-2-$ and non-H-2-linked genes are involved in the persistence of Theiler's virus and susceptibility to TVID [26]. Mice that are $\mathrm{H}-2^{\mathrm{d}, \mathrm{b}, \mathrm{k}}$ are able to effectively clear the virus from the CNS and do not develop TVID, whereas mice that are $\mathrm{H}-2^{\mathrm{s}, \mathrm{v}, \mathrm{q}, \mathrm{r}, \mathrm{f}}$ do not clear the virus from the CNS and eventually develop TVID. However, congenic strains such as B10.S which are $\mathrm{H}-2^{\mathrm{s}}$ on a C57BL/10 background demonstrate reduced severity of TVID $[27,28]$.

It is for these reasons that we have been interested in the mechanisms by which stress can influence the pathogenesis of TMEV infection. In our previous study, psychological stress administered during early infection of TMEV in susceptible SJL mice resulted in an earlier and exacerbated demyelinating disease [29]. We hypothesized that immunosuppression during acute infection induced increased viral titers in the CNS, contributing to earlier onset and exacerbation of TVID. Because adaptive immunity, specifically virus-specific CD8+ T-cell responses, is required for viral clearance from the CNS of nonsusceptible C57BL/6 mice [30], we investigated whether chronic stress during early infection would alter susceptibility of the normally resistant C57BL/6 strain to TVID.

\section{Materials and Methods}

\section{Mice}

Female C57BL/6 mice were purchased from Jackson Laboratories (Bar Harbor, Me., USA). The animals were housed 3-4 per cage and kept on a constant 12-hour light-dark cycle (05.00/ $17.00 \mathrm{~h}$ ). Food and water were available to all mice ad libitum. Upon arrival, mice were equally distributed to cages based on body mass. Before the onset of each experiment, all mice were divided into groups corresponding to infection and stress and allowed to acclimate for 1 week prior to the onset of the experiment. Experiment I was designed to determine the effects of restraint stress (RS) on infection during acute infection with TMEV, and two groups were compared: infected/non-restrained mice (I/NR) were compared to infected/restrained mice (I/R). Experiment II was designed to test the effects of stress on susceptibility to chronic demyelination. I/NR, I/R and sham-infected restrained (NI/R) mouse groups were used. All experiments were approved by the Animal Use and Care Committee at Texas A\&M University.

Virus and Infection

All mice were anesthetized with isoflurane (Vedco, St. Joseph, Mo., USA) prior to the infection. Mice in the infected groups were then injected intracerebrally with approximately $5.0 \times 10^{5} \mathrm{PFU}$ of the BeAn strain of TMEV (kindly provided by Dr. H.L. Lipton, Department of Microbiology and Immunology, University of Illinois, Chicago, Ill., USA), and mice in the non-infected groups were sham-infected intracerebrally with sterile phosphate-buffered saline.

\section{$R S$ Procedure}

RS was carried out by placing mice in a well-ventilated $60-\mathrm{ml}$ syringe as previously described such that they were capable of moving laterally, but not vertically [31]. Briefly, mice in the restraint group were restrained starting 1 day prior to infection for $8 \mathrm{~h}$ per session (12.00-08.00 h). For acute-phase experiments, mice were restrained for 7 consecutive nights. For chronic-phase experiments, mice received a total of 20 restraint sessions consisting of 5 consecutive nights of stress followed by 2 nights with no stress [29].

Physiological Indices of Stress and Infection

The degree of ruffling, an indicator of stress, and body mass were recorded daily during the acute-phase experiments (day 7 or 16 PI) and biweekly during the chronic-phase experiments. The 
degree of ruffling was scored as $0=$ no ruffling, $1=$ ruffling of the head, 2 = ruffling of the head and $50 \%$ of the body, $3=$ ruffling of the head and entire body.

\section{Blood Collection for Radioimmunoassay}

Prior and $48 \mathrm{~h}$ after restraint, mice were bled from the saphenous vein, as previously described, during the hours of 08.00 10.00 [29]. Immediately following collection, plasma was removed after centrifuging at $3,000 \mathrm{~g}$ for $10 \mathrm{~min}$ at $4^{\circ} \mathrm{C}$, and stored at $-80^{\circ} \mathrm{C}$ until corticosterone levels could be determined by radioimmunoassay [32].

\section{Corticosterone Assay}

Plasma samples were assayed in duplicate for corticosterone at baseline (before restraint) and $48 \mathrm{~h}$ after restraint using radioimmunoassay kits obtained from MP Biomedicals (Morgan Irvine, Calif., USA) according to the manufacturer's instructions [32].

\section{NK-Cell Assay}

NK-cell activity was assessed using a standard ${ }^{51} \mathrm{Cr}$ release assay as previously described using splenocytes as effectors and YAC-1 cells as targets [33]. Total ${ }^{51} \mathrm{Cr}$ release was determined by incubating targets with $10 \%$ Triton X-100. Spontaneous release was determined by counting the amount of ${ }^{51} \mathrm{Cr}$ released after incubation of targets in complete RPMI-1640 media. Total lysis of experimental samples was calculated using the following equation: [(experimental release - spontaneous release)/(total release - spontaneous release) $] \times 100$. All samples were run in triplicate.

\section{Antibody Levels}

TMEV-specific antibody levels were measured by an ELISA in serum obtained from each mouse on days 7, 16, 73, 155, and 193 PI. Briefly, high-binding 96-well plates were coated with $0.25-\mu \mathrm{g}$ pelleted TMEV per well overnight at $4{ }^{\circ} \mathrm{C}$. Plates were blocked with Superblock according to the manufacturer's instructions (Pierce, Rockford, Ill., USA). Serum was serially diluted and incubated for $1.5 \mathrm{~h}$ at room temperature. After washing and rinsing, plates were incubated with either peroxidase-conjugated goat anti-mouse IgG (A-5278) or goat anti-mouse IgM (A-8786; Sigma, St. Louis, Mo., USA) for $1 \mathrm{~h}$ at room temperature. After washing and rinsing, reactions were developed with $o$-phenylenediamine (Sigma) for $15 \mathrm{~min}$ after which the reaction was stopped with $2.5 \mathrm{M}$ sulfuric acid.

\section{Cytotoxic T-Lymphocyte Assay}

Cytotoxic T-lymphocyte (CTL) activity was assessed on days 7 and 16 PI using a chromium release assay. Here, previously isolated syngeneic cerebrovascular endothelial (CVE) cells [34] were infected with the BeAn strain of TMEV at a multiplicity of infection of 1 for $24 \mathrm{~h}$. The cells were then radiolabeled with sodium chromate $\left({ }^{51} \mathrm{Cr}-100 \mu \mathrm{Ci} / 2.0 \times 10^{6}\right.$ cells $)$ for $2 \mathrm{~h}$ at $37^{\circ} \mathrm{C}$ and $5.0 \%$ $\mathrm{CO}_{2}$. Single-cell suspensions of spleen cells were made as previously described [33], and added to sterile round-bottom 96-well polystyrene plates at a concentration of $1.0 \times 10^{6}$ cells $/$ well in a total volume of $100 \mu \mathrm{l}$ of medium. Doubling dilutions were made of effectors, and $1.0 \times 10^{4}$ radiolabeled CVE cells per $100 \mu \mathrm{l}$ of medium were added to all wells. Plates were then centrifuged at $500 \mathrm{~g}$ for $1 \mathrm{~min}$. The plate was incubated at $37^{\circ} \mathrm{C}$ and $5.0 \% \mathrm{CO}_{2}$ for $4 \mathrm{~h}$. Cells were pelleted by centrifugation at 2,000 $\mathrm{g}$ for $20 \mathrm{~min}$, and $100 \mu \mathrm{l}$ of the supernatant were removed and counted in a Micromedic $4 / 200$ Plus automatic $\gamma$-counter. Total ${ }^{51} \mathrm{Cr}$ release was determined by adding $100 \mu \mathrm{l}$ of $10 \%$ Triton X-100 to wells containing radiolabeled CVE cells only. Spontaneous release was determined by measuring $100 \mu \mathrm{l}$ of supernatant containing only radiolabeled CVE cells. Percent lysis was calculated using the following formula: [(experimental release - spontaneous release)/ (total release - spontaneous release) $] \times 100$. All samples were assayed in triplicate.

Plaque Assays

Plaque assays were used to determine viral levels in the brains of mice on days 7 and 16 PI, as previously described [35].

\section{Rotarod Analysis}

During the chronic phase of TMEV infection, Rotarod analysis provides an indication of motor dysfunction $[29,36]$. Therefore, all groups were tested for performance on Rotarod starting on day 77 PI using a Ugo Basile (model 7650) accelerating Rotarod treadmill. The amount of time the mouse successfully remained on the rod was recorded for two sessions. Scores were taken biweekly, and results were expressed as the means of two sessions per date.

\section{Histology}

Mice in the chronic-phase experiment were sacrificed on day 193 PI and perfused with PBS followed by $10 \%$ formalin. The brains and spinal cords were isolated, grossly sectioned, dehydrated, embedded in paraffin, sectioned into 5- $\mu \mathrm{m}$ sections and stained with hematoxylin and eosin [29]. Sections were then examined for inflammation and demyelination.

\section{Statistics}

Data are presented as means \pm SEM. Data were analyzed using analysis of variance and repeated-measures analysis of variance. The Mann-Whitney nonparametric analysis test was used to analyze differences in acute ruffling scores between I/NR and I/R groups. The Friedman test repeated-measure nonparametric analysis was used to assess differences in ruffling scores between I/NR, I/R and NI/R groups. When appropriate, Fisher's protected least-significant difference or Dunn's multiple-comparison model were used as post hoc tests to establish differences between groups. In all cases, significance was set at $\mathrm{p} \leq 0.05$.

\section{Results}

\section{Experiment I: Effects of RS on Early Disease in C57Bl/6 Mice}

Indices of Stress

Mice subjected to RS typically display ruffled fur and decreased body weight [29]. As seen in figure 1, stress caused a significant decrease in body weight, which corresponded to the period in which mice were receiving nightly RS sessions (days $1-7 \mathrm{PI})[\mathrm{F}(1,20)=8.283$; $\mathrm{p}<0.01$ (fig. 1a)]. This effect was immediately diminished following the termination of these sessions, and no differences 
Fig. 1. RS decreases body weight and causes ruffling in TMEV-infected C57BL/6 mice. a During the RS period (solid black line), I/R mice showed significant weight loss compared to I/NR mice. b RS significantly increases ruffling scores in I/R versus I/NR mice during the restraint period. a, $\mathbf{b}$ These effects were quickly diminished after the termination of RS sessions.
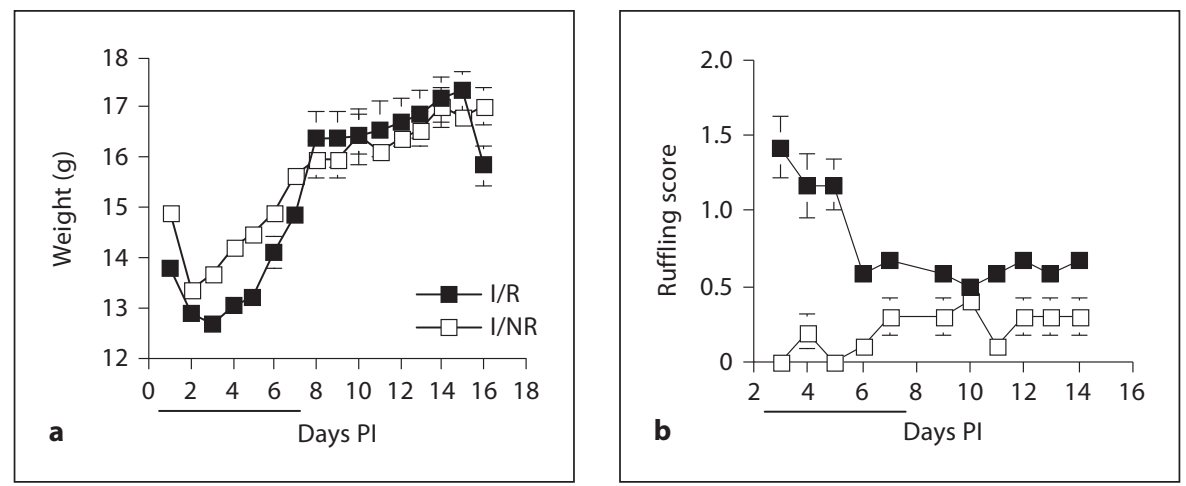

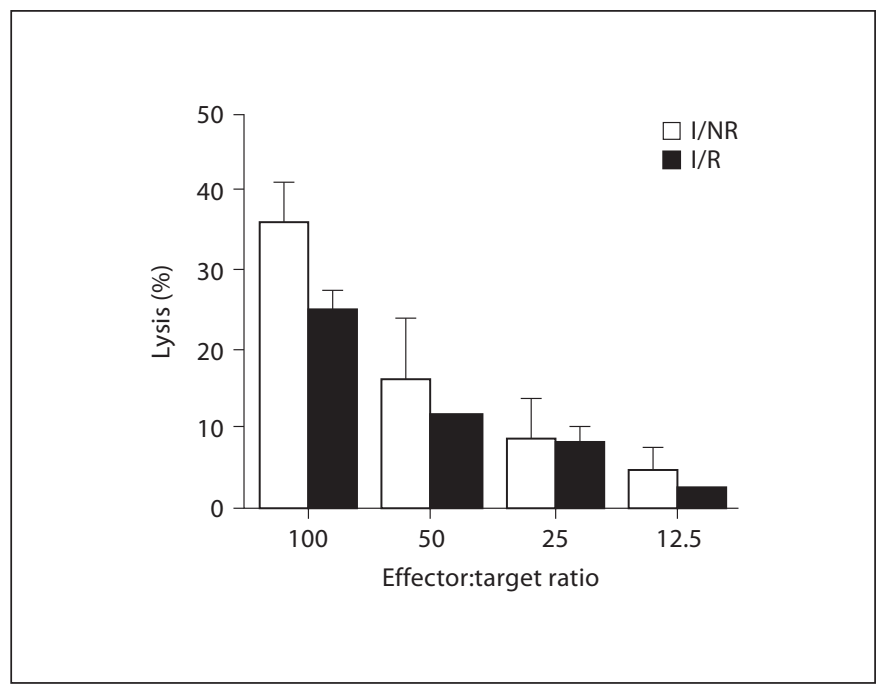

Fig. 2. Effect of RS decreases NK-cell lysis on day 1 PI. Mice were stressed by restraint 1 day prior to infection with TMEV. On day 1 PI, splenic NK-cell effector function was measured by chromium release assay using YAC-1 cells as targets. At an effector:target ratio of 100:1, I/R mice $(n=5)$ displayed a trend towards reduced capacity to lyse targets compared with $\mathrm{I} / \mathrm{NR}$ mice $(\mathrm{n}=4 ; \mathrm{p}=$ 0.068). Means \pm SEM.

between $\mathrm{I} / \mathrm{NR}$ and $\mathrm{I} / \mathrm{R}$ mice were seen for the duration of the experiment (days 8-16 PI) $[\mathrm{F}(1,9)=0.058 ; \mathrm{p}=0.815$ (fig. 1a)]. In contrast, mice in the I/R group displayed increased ruffling scores when compared to I/NR mice (fig. 1b). This effect was significant on days 1-7 PI, corresponding to the time in which $\mathrm{I} / \mathrm{R}$ mice were being stressed (Mann-Whitney test; $\mathrm{p}=0.0079$ ). However, I/R mice remained more ruffled than I/NR mice even after stress sessions had ceased (days 8-16 PI; Mann-Whitney test; $\mathrm{p}=0.0022$; fig. $1 \mathrm{~b})$.
Effects of RS on NK-Cell Lysis

Previous experiments indicated day $1 \mathrm{PI}$ as having the most significant virus-specific increases in NK-cell lysis [33]. Therefore, this time point was used to determine the effects of stress on NK-cell effector function. As depicted in figure 2, we detected a trend for stress to decrease NKcell lysis of YAC-1 target cells from $36 \%$ in I/NR mice to approximately $25 \%$ in I/R mice, accounting for a reduction of about $11 \%(\mathrm{p}=0.068)$. A significant reduction in NK-cell activity would indicate a decrease in innate immune processes [37].

\section{Effects of RS on Adaptive Immune Responses to \\ TMEV on Days 7 and 16 PI}

The resistance of C57BL/6 mice to TVID is due to their ability to effectively clear TMEV from the CNS during early infection. Previously, we have shown that most viruses are eliminated from the CNS of these mice by day $16 \mathrm{PI}$ after intracerebral inoculation [38]. Early clearance in C57BL/6 mice has been attributed to the generation of a robust adaptive immune response, which utilizes both cellular and humoral immunity [39]. We determined the effects of RS on these responses on days 7 and 16 PI. Interestingly, on day $7 \mathrm{PI}$, no differences were detected between groups although it appeared that $\mathrm{I} / \mathrm{R}$ mice had reduced spleen mass (106 $\pm 23 \mathrm{mg}$ ) compared to I/NR mice $(158 \pm 14 \mathrm{mg})$, but this effect was not statistically significant $[F(1,9)=3.478 ; p=0.095$ (fig. 3a)]. Likewise, on day $16 \mathrm{PI}$, no differences between I/R and I/NR groups were detected (fig. 3a), being in sharp contrast to the effects of stress on CBA mice [33].

The CTL response plays a major role in TMEV clearance and resistance to demyelination in $\mathrm{C} 57 \mathrm{BL} / 6$ mice [30]. In these mice, the CTL response is detectable as early as 5 days PI, peaks between days 7-10 PI and resolves with viral clearance by day 16 PI [38]. Using infected 
Fig. 3. Effects of RS on adaptive immune responses to TMEV on days 7 and 16 PI. a Effects of RS on spleen weight on day 7 and 16 PI. b, c Splenic CTL responses against infected (multiplicity of infection = 1) CVE cells on day 7 (b) and 16 PI (c). d, e Serum anti-TMEV IgM levels on both day 7 (d) and 16 PI (e). f, g Serum IgG levels to TMEV on days $7(\mathbf{f})$ and $16(\mathbf{g})$. Means \pm SEM.
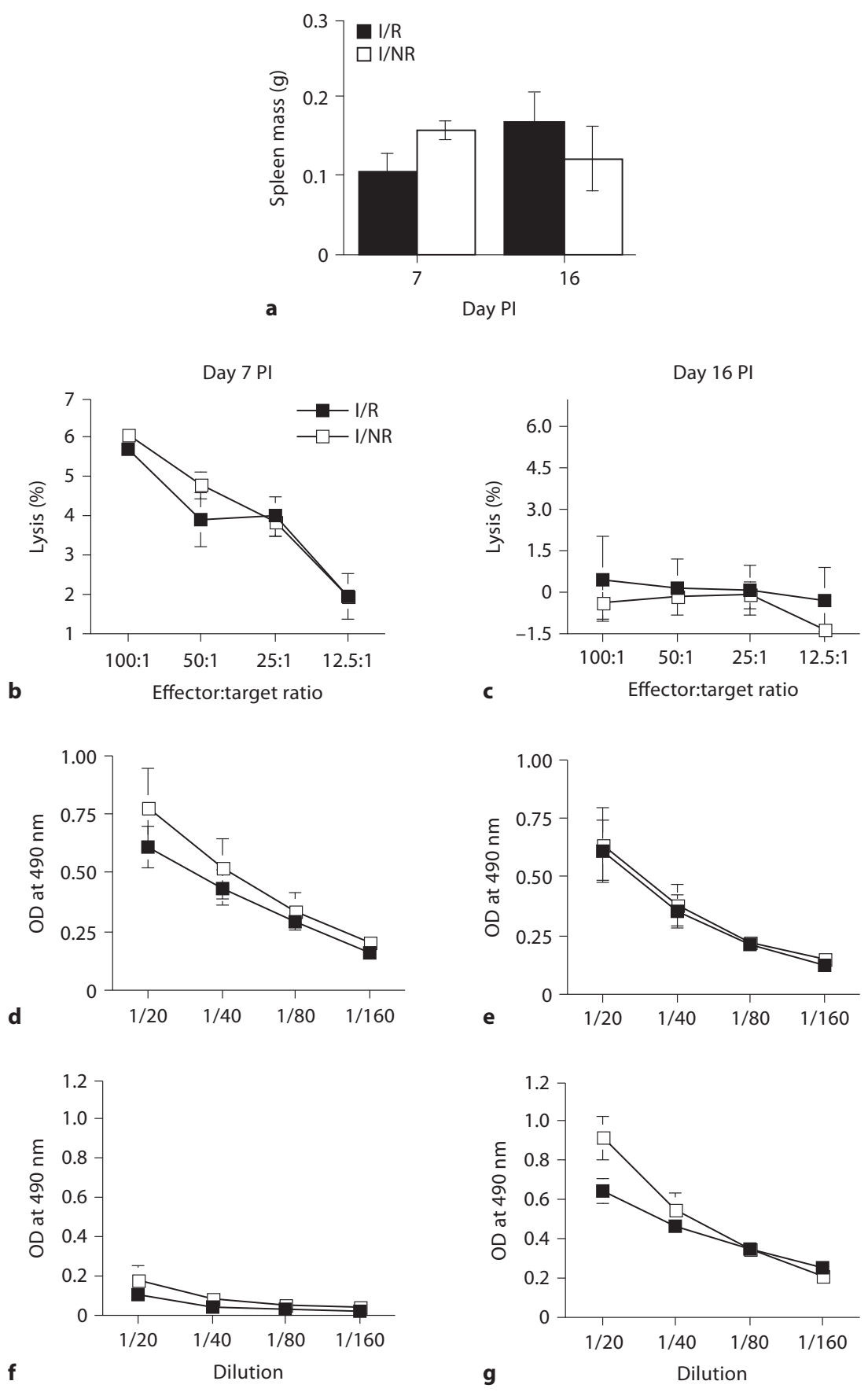

cloned syngeneic CVE cells as targets in a chromium release assay, we observed no differences between I/NR and I/R groups (fig. 3b) on day 7 PI. By day $16 \mathrm{PI}$, the CTL response had abated and was undetectable in I/NR and I/R mice groups (fig. 3c).

Effect of Restraint Stress on Theiler's Virus-Induced Demyelination
Antibody responses directed toward TMEV have also been shown to limit viral persistence in the absence of a $\mathrm{CD}^{+} \mathrm{T}$-cell response [39]. Therefore, we measured the effects of stress on virus-specific IgM and IgG responses by ELISA. We found no stress-induced differences in IgM 


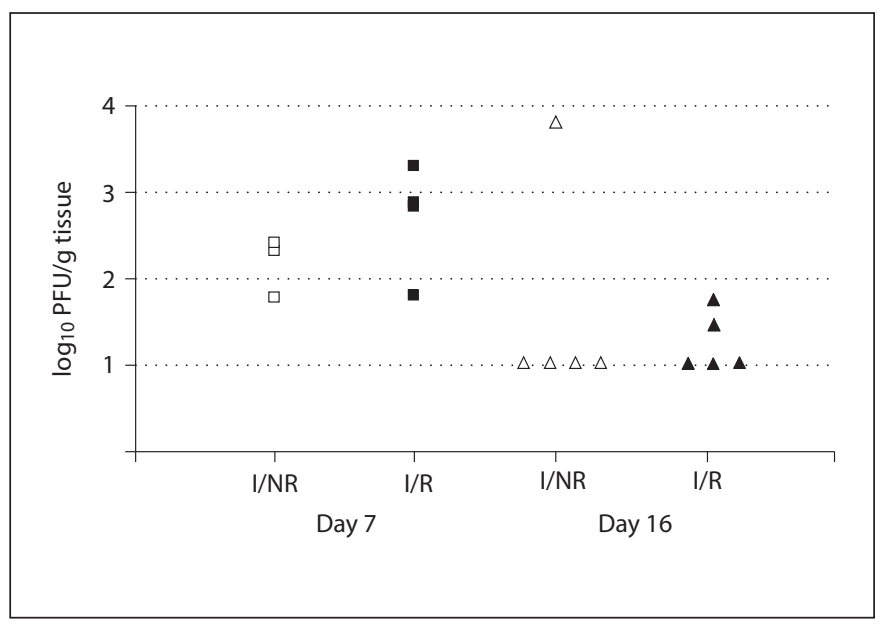

Fig. 4. Effects of RS on brain viral titers on day 7 and 16 PI. Brain viral titers were measured by plaque assay on days 7 and $16 \mathrm{PI}$. I/R mice had slightly higher levels of virus on day 7 PI (left) than I/NR, but the effect was not significant. By day 16 PI (right), both $\mathrm{I} / \mathrm{R}$ and I/NR mice had low or undetectable levels of virus in the brain, and no effect of RS was noted.

responses on either day 7 or 16 PI. Additionally, the virusspecific IgM response did not differ between days 7 and 16 PI (fig. 3d, e). In contrast to the IgM response, virusspecific IgG was almost undetectable on day $7 \mathrm{PI}$, but was substantially increased by day 16 PI $[\mathrm{F}(1,19)=88.682 ; \mathrm{p}<$ 0.0001 (fig. 3f, g)].

However, RS was not found to significantly influence virus-specific IgG levels at either time point (fig. $3 \mathrm{f}, \mathrm{g}, 4$ ). Taken together, these results indicate that RS did not significantly alter virus-specific immune responses on either day 7 or $16 \mathrm{PI}$ in C57BL/6 mice.

\section{Effects of RS on Brain Viral Titers}

In order to determine the effects of RS on viral persistence within the CNS, we used plaque assays to measure viral titers from brains on days 7 and 16 PI. Figure 4 illustrates the effect of RS on brain viral titers. Collectively, viral titers were highest on day 7 PI compared to day 16 PI (fig. 4). Although there was a trend for I/R mice to develop slightly higher viral titers than I/NR mice on day 7 PI, this finding was not statistically significant $[F(1,9)=$ 1.642; $p>0.05$ (fig. 4)]. In addition, there were no significant differences between I/R and I/NR groups with respect to viral titer (fig. 4). These results indicate that RS did not substantially alter the ability of mice to clear virus from the CNS in C57BL/6 mice.
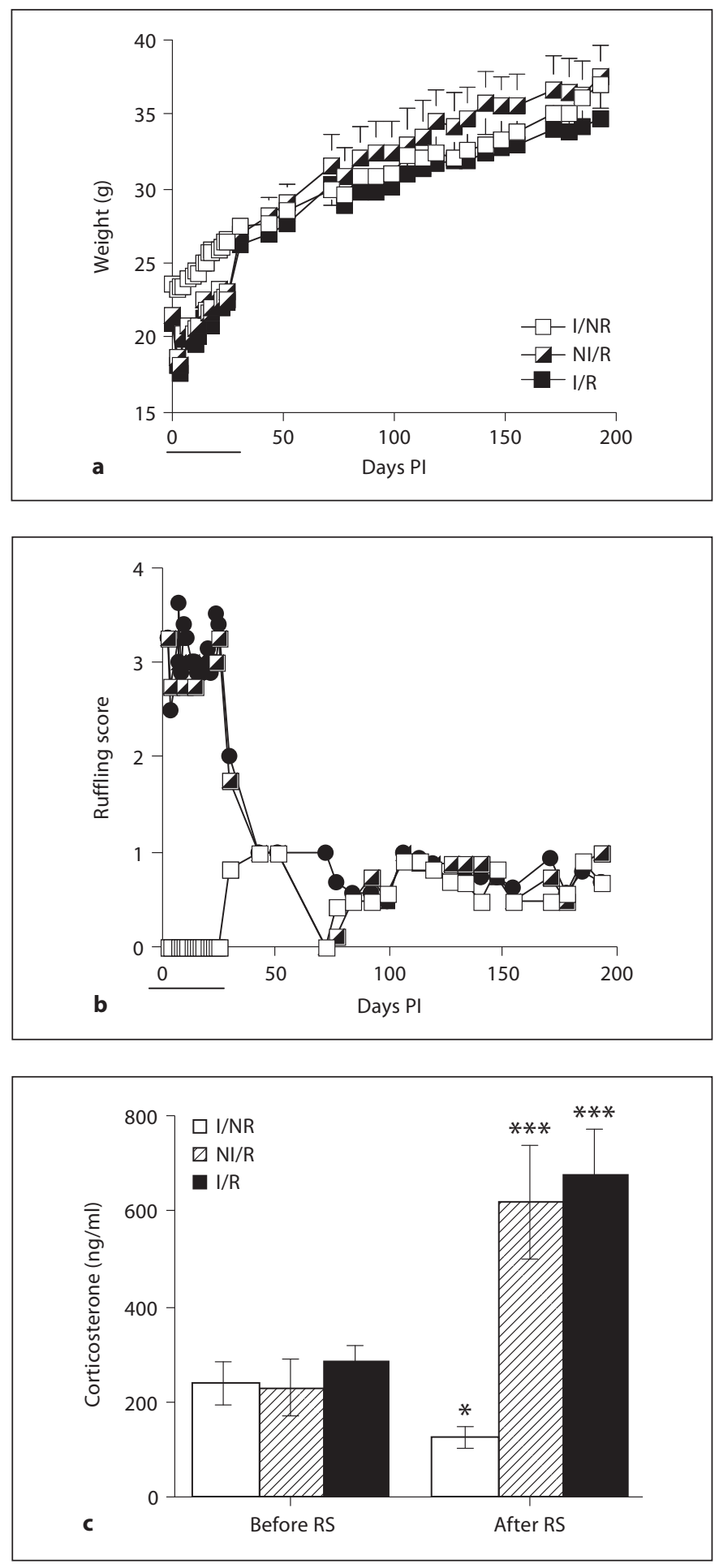

Fig. 5. Effects of infection and RS on weight, ruffling score and plasma corticosterone. a, b Restrained mice displayed decreased body weight (a) and ruffling scores (b) compared to non-restrained mice during the RS period (solid black line), but this effect quickly subsided following the RS period (a, b). c Plasma corticosterone levels $48 \mathrm{~h}$ after the first RS session (day $1 \mathrm{PI}$; c). Means $\pm \operatorname{SEM}\left({ }^{*} \mathrm{p}<0.05,{ }^{* * *} \mathrm{p}<0.001\right.$ vs. controls before RS). 

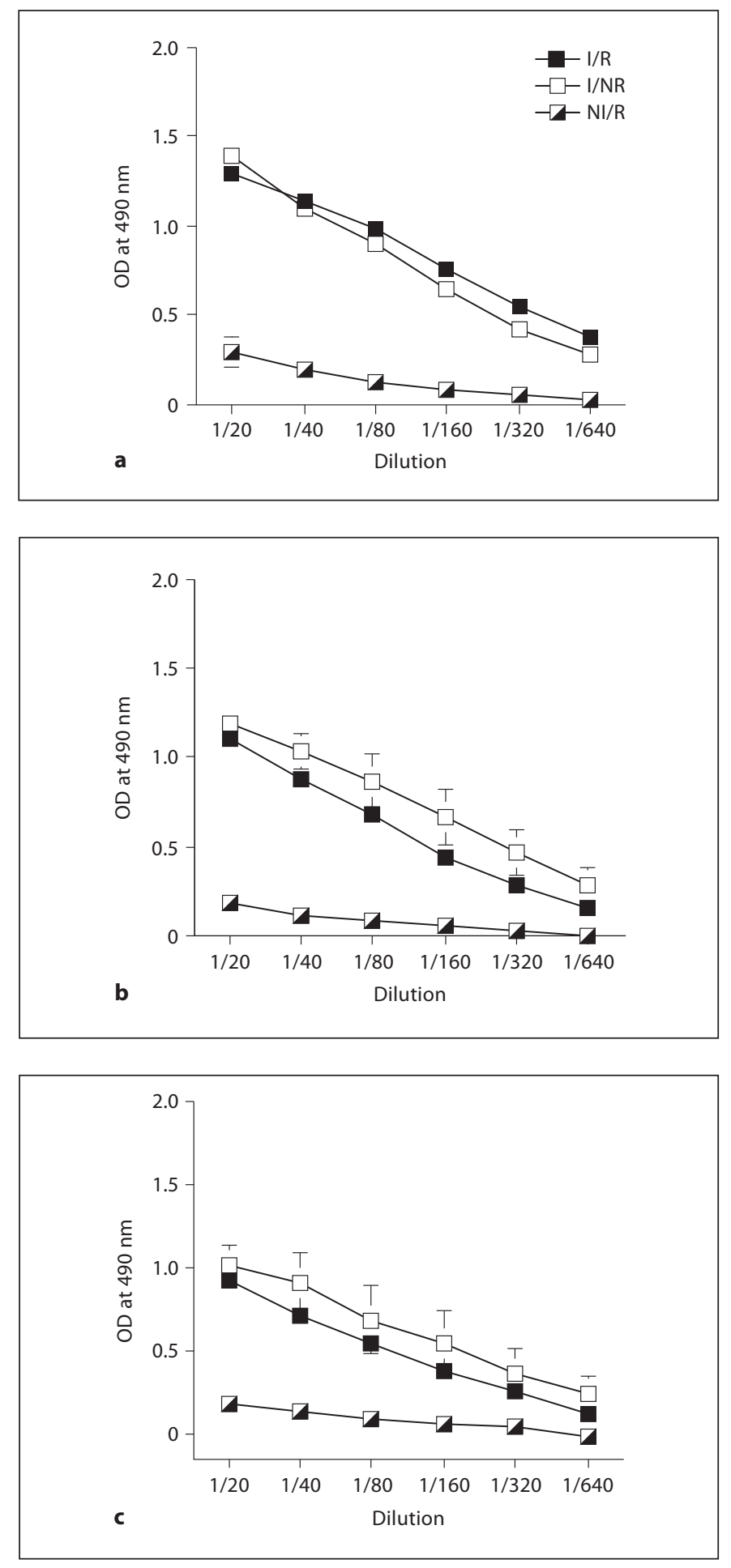

Fig. 6. Effects of RS on serum virus-specific IgG responses to TMEV on days 73, 155, and 195 PI (a-c). Virus-specific antibody levels on days 73 (a), 155 (b) and 193 (c) PI. Means \pm SEM.

\section{Experiment II: The Effect of RS on Late TMEV in C57Bl/6 Mice}

Results from our first experiment indicated that 8 consecutive RS sessions each lasting $8 \mathrm{~h}$ did not significantly alter either virus-specific adaptive immunity or viral persistence in the early phases of TMEV infection. Due to the age of our mice (3-5 weeks old), we could not increase the length of each stress session without expecting high mortality rates [40]. Therefore, we altered the number of RS sessions such that mice received 5 consecutive nights of RS with a 2-night rest inbetween, for a total of 20 RS sessions [29]. To ensure that the 8-hour RS was acting as a stressor in C57BL/6 mice, we measured plasma corticosterone before and immediately after the second RS session as an indicator of hypothalamic-pituitary-adrenal axis activation [29]. C57BL/6 mice do not develop demyelination following infection with TMEV. However, in order to determine the effects of RS on altered susceptibility to TMEV, we included NI/R mice as a control group.

Effects of Stress on Body Weights, Ruffling and

Plasma Corticosterone

As in experiment I, we found that RS significantly decreased the body weights of mice in the restrained groups (I/R and NI/R) during the period in which the mice were receiving nightly $R S$ sessions $[F(1,12)=42.238 ; \mathrm{p}<0.0001$; days $0-25$ PI (fig. 5a)]. Body weights quickly returned to levels comparable to I/NR mice immediately following cessation of RS sessions and were not found to differ again for the duration of the experiment (days 30-193; fig. 5a). In contrast, infection with TMEV had no effect on body weights (fig. 5a).

Also, ruffling scores were significantly increased during days $0-25$ PI (Friedman test; $\mathrm{p}<0.001$; fig. 5b). As with body weights, these scores became indistinguishable between groups following the RS period (days 30195 PI) for mice in the restrained groups (fig. 5b). Once again, infection did not alter signs of ruffling at any time point (fig. 5b).

As illustrated by figure $5 c$, RS significantly increased plasma concentrations of corticosterone in $\mathrm{I} / \mathrm{R}$ and $\mathrm{NI} / \mathrm{R}$ mice compared to $\mathrm{I} / \mathrm{NR}$ mice $[\mathrm{F}(1,18)=21.752 ; \mathrm{p}<0.0001]$, demonstrating hypothalamic-pituitary-adrenal axis activation following stress. Infection had no influence on plasma concentration of corticosterone (fig. 5c).

Effects of Stress on TMEV-Specific Antibody Levels on Days 73, 155 and 193 PI

Virus-specific IgG antibody levels were used as indicators of adaptive immunity during the late phase of 
Fig. 7. Effects of RS on indices of demyelination. No differences were detected between I/R, I/NR or NI/R groups by Rotarod (a). HE staining of CNS tissue isolated on day 193 PI demonstrated no inflammation, demyelination or microgliosis in I/R mice (b), whereas spinal cord tissue from an age-matched infected SJL mouse showed inflammation and demyelination; arrows show meningitis (left) and parenchymal inflammation (right; c).
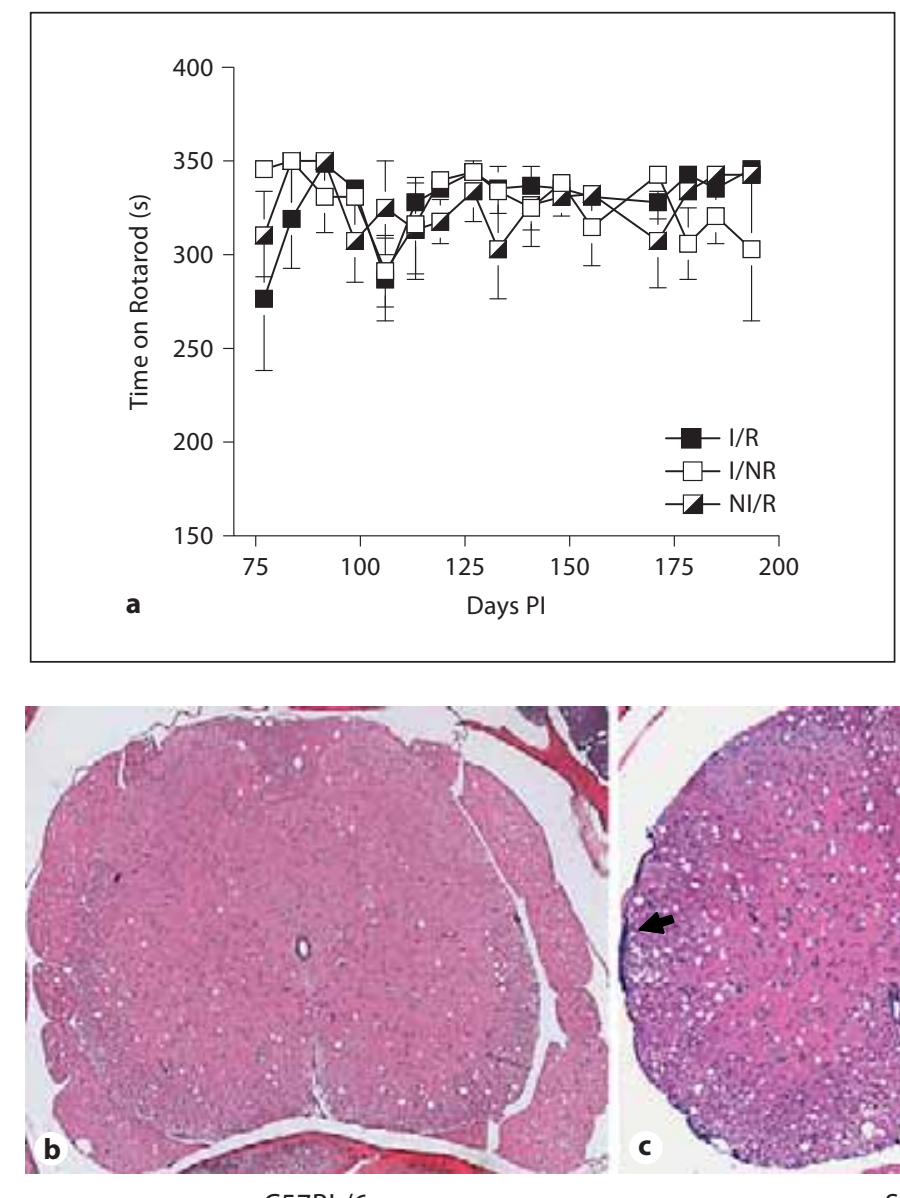

C57BL/6

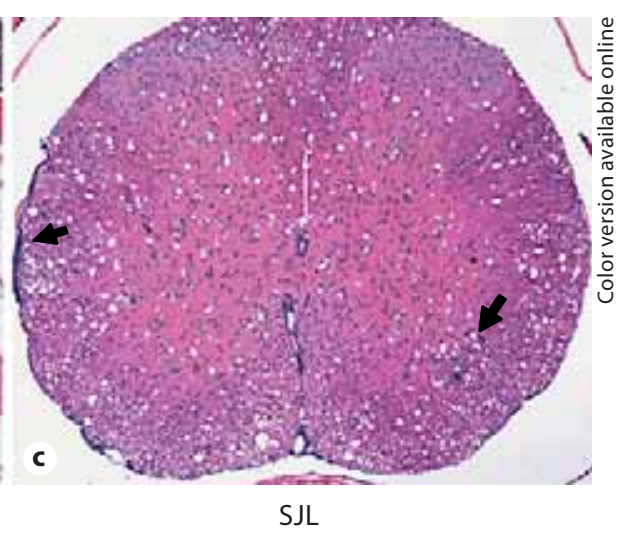

TMEV infection. Infection with TMEV resulted in substantially increased antibody levels on days 73, 155 and up to 193 PI (fig. 6). However, as before, RS did not affect the humoral response to TMEV at any of these time points (fig. 6). These results indicate that despite 20 sessions of RS occurring during early infection with TMEV, the mice in the I/R group were still able to mount a robust antibody-mediated immune response toward TMEV.

\section{Effects of Stress on Indices of Demyelination}

Susceptible mice infected with TMEV, such as the SJL strain, display clinical symptoms of demyelination, including a wobbly gait, abnormal righting reflex, a hunched posture, and ruffling of the fur. The onset of these symptoms typically begins around $40-55$ days p.i. and progressively worsens as the animal ages. However, as hunched posture and ruffled fur can also be used to assess degree of stress (fig. $1 b, 5 b$ ), we focused primarily on gait score as an indication of disease onset. Additionally, we tested motor responses by Rotarod biweekly. No mouse developed signs of gait abnormality at any time during the experiment (not shown). Moreover, as seen in figure 7a, neither infection nor RS altered the degree of motor capability determined by Rotarod analysis. Finally, histological analysis of spinal cords from I/R mice demonstrated no inflammation, demyelination or microgliosis (fig. 7b).

\section{Discussion}

RS has been shown to drastically influence immunity to viral infections. For instance, immediately preceding and following influenza infection, stress has been reported to decrease: NK-cell activity [41, 42]; CTL responses [43], and mononuclear-cell infiltration into [44] and IL-2 production in the lungs [45]. Likewise, RS has also been shown to downregulate CTL, NK and IL-2 responses to experimental herpes simplex virus infection [46], leading to increases in virus-induced encephalitis [47], as well as 
its reactivation from the trigeminal nerves of infected mice [48].

During early infection with TMEV, RS CBA mice develop decreased NK-cell activity [33] and chemokine/cytokine expression in the brains and spleens, as well as altered viral dissemination and viral load $[31,35,49]$. Additionally, in SJL mice, RS suppresses virus-specific T-cell responses in the CNS as well as the periphery [50], which may result in an exacerbated late disease [29].

Based on our previous findings, as well as those of others, we hypothesized that RS would cause suppression of innate and adaptive immune responses toward TMEV in C57BL/6 mice - responses that are needed for viral clearance and inhibition of viral persistence from the CNS in this prototypical TMEV-resistant inbred strain [51, 52]. Therefore, as occurs in susceptible strains of mice, we hypothesized that this immunosuppression would result in increased viral load in the CNS, possibly leading to persistence and the subsequent development of TVID. Our results overwhelmingly demonstrate that RS does not alter susceptibility of C57BL/6 mice to TMEV, and failed to significantly suppress the development of both antibody and CTL responses directed toward TMEV (fig. 3). These findings mirror the inability of RS to significantly influence viral load within the CNS of C57BL/6 mice infected with Theiler's virus (fig. 4). While this effect of stress on the TMEV-specific humoral responses agree with the findings on the effects of repeated 16-hour sessions of RS on virus-specific humoral responses to influenza $[45,53]$, our data demonstrating a lack of an effect on TMEV-specific CTL responses are in contrast to the findings of others that clearly demonstrate suppressive effects of repeated RS on CTL effector function [46, 43, 48]. One reason for the discrepancy between our data and those of others may be attributable to the subtle differences in the assays used to test the CTL response. While others have successfully used radiolabeled splenocytes as target cells, we chose to employ the use of cloned CVE cells, a suspected target of in vivo infection of TMEV and possibly persistence [54]. While the degree of lysis is low compared to conventional assays, we believe that they accurately reflect the events occurring in vivo, which is illustrated by the fact that CNS viral load did not significantly differ between I/NR and I/R groups during the same time frame. Conversely, despite obvious differences in body weight and the increases in ruffling scores due to RS, we have also entertained the possibility that our mice were not stressed. However, RS clearly resulted in the release of corticosterone into the blood (fig. 5c), which is an accepted marker of hypothalamic-pituitary-adrenal axis activation. Moreover, these concentrations have been shown to correlate with immunosuppression in other strains of mice [29].

Alternatively, this paradox may be explained in several ways. First, the age of the animals. Stress studies usually use mice over the age of 8 weeks. In our experiments, we used 4- to 6-week-old mice due to the fact that older animals become resistant to Theiler's virus infection [55]. Second, while our mice were certainly stressed, their allostatic load may not have been increased enough to cause immunologic distress [56]. Allostasis is a concept developed by Bruce McEwen to describe the active adaptive processes that maintain homeostasis and the consequences of sustained or repeated activation of mediators of allostasis. This concept is supported by findings of others that demonstrate the importance of the timing and duration of a stressor as well as the influence of the genetic background on the immune response [57]. C57BL/6 mice have previously been reported to have a low or intermediate stress response in comparison to other strains of mice $[58,59]$. Eight-week-old C57BL/6 mice have lower basal corticosterone levels, develop lower/intermediate levels of corticosterone in response to acute uncontrollable foot shock and their plasma corticosterone levels rapidly return to basal levels after shock, too [58].

As mentioned previously, C57BL/6 mice are capable of generating a very effective early immune response toward TMEV [60]. Therefore, it could be possible that the antigenic stimulus alters the allostatic set point for when stress becomes distress. In this scenario, an equivalent amount of stress is likely to differentially affect the immunologic outcome of any given pathogenic stimuli based on its degree of immunogenicity. This could explain why the same dose of stress differentially affects viral titers in inbred mouse strains of varying susceptibility to TMEV.

MS onset is thought to be influenced by multiple factors [1]. Of these factors, psychological stress has been repeatedly associated with MS since around the time of its initial characterization by Charcot [61]. However, whereas most studies support a role of stress in the pathogenesis of MS [22], another study has demonstrated a lack of association between stressful life events and exacerbation of MS [62]. Using TMEV as a model for human MS, we have now demonstrated the ability of C57BL/6 mice to prevent persistent viral infection of the CNS despite being subjected to a chronic stressor during a critical time in the determination of viral persistence [60]. As such, this study may have important implications when considering the effects of stress on human diseases such 
as MS. For instance, different populations may vary in response to stress or have different allostatic set points, such that the perception of a similar stressor may not necessarily trigger a uniform distress in different individuals. This could explain why chronic stressors in certain populations are strongly linked to MS onset [21] and exacerbations [20], whereas other chronic stressors occurring in different populations are not linked to MS exacerbations [62].

In conclusion, RS did not alter susceptibility to TMEVinduced demyelination of C57BL/6 mice. However, our data pave the way to elucidate the role of the genetic background, immunologic responses, and environmental factors that contribute to virus-induced demyelination, in a sense validating the use of RS and TMEV infection as a model of human MS. At the very least, this study empha- sizes the importance of using different inbred strains of mice to address the role of stress on host-pathogen relationships.

\section{Acknowledgments}

The authors would like to thank Dr. Weston Porter (Department of Veterinary Integrative Biosciences, Texas A\&M University, College Station, Texas) for the use of his spectrophotometer. This research was funded by grants to C.J.R.W. and M.W.M. from the National Multiple Sclerosis Society RG 3128 and NIH/NINDS R01 39569. A.J.S. received support from the Recovery of Function Graduate Training Program at Texas A\&M University and NIH/ NRSA 5T32AI052072-05. This work was performed in partial fulfillment of the requirements for the $\mathrm{PhD}$ degree for A.J.S. at Texas A\&M University.

\section{References}

1 Hauser SL, Oksenberg JR: The neurobiology of multiple sclerosis: genes, inflammation, and neurodegeneration. Neuron 2006;52: 61-76.

2 Cermelli C, Jacobson S: Viruses and multiple sclerosis. Viral Immunol 2000;13:255-267.

3 Sibley WA, Bamford CR, Clark K: Clinical viral infections and multiple sclerosis. Lancet 1985;i:1313-1315.

4 Panitch HS: Influence of infection on exacerbations of multiple sclerosis. Ann Neurol 1994;36(suppl):S25-S28.

5 Kurtzke JF, Heltberg A: Multiple sclerosis in the Faroe Islands: an epitome. J Clin Epidemiol 2001;54:1-22.

6 Tenembaum S, Chitnis T, Ness J, Hahn JS: Acute disseminated encephalomyelitis. Neurology 2007;68(suppl 2):S23-S36.

7 Sips GJ, Chesik D, Glazenburg L, Wilschut J, De Keyser J, Wilczak N: Involvement of morbilliviruses in the pathogenesis of demyelinating disease. Rev Med Virol 2007;4:223244.

8 Sigurdsson B, Palsson P, Grimsson H: Visna, a demyelinating transmissible disease of sheep. J Neuropathol Exp Neurol 1957;16: 389-403.

9 Wiśniewski H, Raine CS, Kay WJ: Observations on viral demyelinating encephalomyelitis. Canine distemper. Lab Invest 1972;26: 589-599.

10 Weiner LP: Pathogenesis of demyelination induced by a mouse hepatitis. Arch Neurol 1973;28:298-303.

11 Daniels JB, Pappenheimer AM, Richardson S: Observations on encephalomyelitis of mice (DA strain). J Exp Med 1952;96:517530.
12 Lipton HL: Theiler's virus infection in mice: an unusual biphasic disease process leading to demyelination. Infect Immun 1975;11: 1147-1155.

13 Ebers GC, Bulman DE, Sadovnick AD, Paty DW, Warren S, Hader W, Murray TJ, Seland TP, Duquette P, Grey T, et al: A populationbased study of multiple sclerosis in twins. N Engl J Med 1986;315:1638-1642.

14 Willer CJ, Dyment DA, Risch NJ, Sadovnick AD, Ebers GC, Canadian Collaborative Study Group: Twin concordance and sibling recurrence rates in multiple sclerosis. Proc Natl Acad Sci USA 2003;100:12877-12882.

15 Hansen T, Skytthe A, Stenager E, Petersen HC, Kyvik KO, Brønnum-Hansen H: Risk for multiple sclerosis in dizygotic and monozygotic twins. Mult Scler 2005;11:500-503.

16 Hansen T, Skytthe A, Stenager E, Petersen HC, Brønnum-Hansen H, Kyvik KO: Concordance for multiple sclerosis in Danish twins: an update of a nationwide study. Mult Scler 2005;11:504-510.

17 Dyment DA, Ebers GC, Sadovnick AD: Genetics of multiple sclerosis. Lancet Neurol 2004;3:104-110.

18 Haines JL, Terwedow HA, Burgess K, Pericak-Vance MA, Rimmler JB, Martin ER, Oksenberg JR, Lincoln R, Zhang DY, Banatao DR, Gatto N, Goodkin DE, Hauser SL: Linkage of the MHC to familial multiple sclerosis suggests genetic heterogeneity. The Multiple Sclerosis Genetics Group. Hum Mol Genet 1998;7:1229-1234.

19 Warren S, Greenhill S, Warren KG: Emotional stress and the development of multiple sclerosis: Case-control evidence of a relationship. J Chronic Dis 1982;35:821-831.
20 Grant I, Brown GW, Harris T, McDonald WI, Patterson T, Trimble MR: Severely threatening events and marked life difficulties preceding onset or exacerbation of multiple sclerosis. J Neurol Rehab 1989;52:8-13.

$21 \mathrm{Li} \mathrm{J}$, Johansen C, Bronnum-Hansen $\mathrm{H}$, Stenager E, Koch-Henriksen N, Olsen J: The risk of multiple sclerosis in bereaved parents. Neurology 2004;62;726-729.

22 Mohr DC, Hart SL, Julian L, Cox D, Pelletier D: Association between stressful life events and exacerbation in multiple sclerosis: a meta-analysis. BMJ 2004;328:731-735.

23 Brown RF, Tennant CC, Sharrock M, Hodgkinson S, Dunn SM, Pollard JD: Relationship between stress and relapse in multiple sclerosis: Part I. Important features. Mult Scler 2006;12:453-464.

24 Brown RF, Tennant CC, Sharrock M, Hodgkinson S, Dunn SM, Pollard JD: Relationship between stress and relapse in multiple sclerosis: Part II. Direct and indirect relationships. Mult Scler 2006;12:465-474.

25 Theiler M: Spontaneous encephalomyelitis of mice - a new virus disease. Science 1934; 80:122.

26 Brahic M, Bureau JF, Michiels T: The genetics of the persistent infection and demyelinating disease caused by Theiler's virus. Annu Rev Microb 2005;59:279-298.

27 Azoulay-Cayla A, Dethlefs S, Pérarnau B, Larsson-Sciard EL, Lemonnier FA, Brahic M, Bureau JF: H-2D(b-/-) mice are susceptible to persistent infection by Theiler's virus. J Virol 2000;74:5470-5476.

Steelman/Alford/Young/Welsh/ Meagher/Welsh 
28 Rodriguez M, Lafuse WP, Leibowitz J, David CS: Partial suppression of Theiler's virus-induced demyelination in vivo by administration of monoclonal antibodies to immuneresponse gene products (Ia antigens). Neurology 1986;36:964-970.

29 Sieve AN, Steelman AJ, Young CR, Storts R, Welsh TH, Welsh CJR, Meagher MW: Chronic restraint stress during early Theiler's virus infection exacerbates the subsequent demyelinating disease in SJL mice. J Neuroimmunol 2004;155:103-118.

30 Mendez-Fernandez YV, Johnson AJ, Rodriguez M, Pease LR: Clearance of Theiler's virus infection depends on the ability to generate a CD8+ T cell response against a single immunodominant viral peptide. Eur J Immunol 2003;33:2501-2510.

31 Mi W, Prentice TW, Young CR, Johnson RR, Sieve AN, Meagher MW, Welsh CJR: Restraint stress decreases virus-induced proinflammatory cytokine expression during acute Theiler's virus infection. J Neuroimmunol 2006;178:49-61.

32 Keith LD, Winslow JR, Reynolds RW: A general procedure for estimation of corticosteroid response in individual rats. Steroids 1974;4:523-531.

33 Welsh CJR, Bustamante L, Nayak M, Welsh TH, Dean DD, Meagher MW: The effects of restraint stress on the neuropathogenesis of Theiler's virus infection II: NK cell function and cytokine levels in acute disease. Brain Behav Immun 2004;18:166-174.

34 Sapatino BV, Petrescu AD, Rosenbaum BA, Smith R 3rd, Piedrahita JA, Welsh CJ: Characteristics of cloned cerebrovascular endothelial cells following infection with Theiler's virus. II. Persistent infection. J Neuroimmunol 1995;62:127-135.

35 Mi W, Young CR, Storts RW, Steelman AJ, Meagher MW, Welsh CJ: Restraint stress facilitates systemic dissemination of Theiler's virus and alters its pathogenecity. Microb Pathog 2006;41:133-143.

36 McGavern DB, Zoecklein L, Drescher KM, Rodriguez M: Quantitative assessment of neurologic deficits in a chronic progressive murine model of CNS demyelination. Exp Neurol 1999;158:171-181.

37 Paya CV, Patick AK, Leibson PJ, Rodriguez M: Role of natural killer cells as immune effectors in encephalitis and demyelination induced by Theiler's virus. J Immunol 1989; 143:95-102.

38 Dethlefs S, Brahic M, Larsson-Sciard E: An early, abundant cytotoxic T lymphocyte response against Theiler's virus is critical for preventing viral persistence. J Virol 1997; 711:8875-8878.
39 Kang BS, Palma JP, Lyman MA, Dal Canto M, Kim BS: Antibody response is required for protection from Theiler's virus-induced encephalitis in C57BL/6 mice in the absence of CD8+ cells. Virology 2005;340:84-94.

40 Campbell T, Meagher MW, Sieve A, Scott B, Storts R, Welsh TH, Welsh CJR: The effects of restraint stress on the neuropathogenesis of Theiler's virus infection: I. Acute disease. Brain Behav Immun 2001;15:235-254.

41 Tseng RJ, Padgett DA, Dhabhar FS, Engler H, Sheridan JF: Stress-induced modulation of NK activity during influenza viral infection: role of glucocorticoids and opioids. Brain Behav Immun 2005;19:153-164.

42 Hunzeker J, Padgett DA, Sheridan PA, Dhabhar FS, Sheridan JF: Modulation of natural killer cell activity by restraint stress during influenza A/PR8 infection in mice. Brain Behav Immun 2004;18:526-535.

43 Sheridan JF, Dobbs C, Jung J, Chu X, Konstantinos A, Padgett D, Glaser R: Stress-induced neuroendocrine modulation of viral pathogenesis and immunity. Ann NY Acad Sci 1998;840:803-808.

44 Hermann G, Beck FM, Sheridan JF: Stressinduced glucocorticoid response modulates mononuclear cell trafficking during an experimental influenza viral infection. J Neuroimmunol 1995;56:179-186.

45 Sheridan JF, Feng N, Bonneau RH, Allen CM, Huneycutt BS, Glaser R: Restraint stress differentially affects anti-viral cellular and humoral immune responses in mice. J Neuroimmunol 1991;31:245-255.

46 Bonneau RH, Sheridan JF, Feng NG, Glaser $\mathrm{R}$ : Stress-induced suppression of herpes simplex virus (HSV)-specific cytotoxic T lymphocyte and natural killer cell activity and enhancement of acute pathogenesis following local HSV infection. Brain Behav Immun 1991;5:170-192.

47 Anglen CS, Truckenmiller ME, Schell TD, Bonneau RH: The dual role of CD8+ T lymphocytes in the development of stress-induced herpes simplex encephalitis. J Neuroimmunol 2003;140:13-27.

48 Freeman ML, Sheridan BS, Bonneau RH, Hendricks RL: Psychological stress compromises CD8+ T cell control of latent herpes simplex virus type 1 infections. J Immunol 2007;179:322-328

49 Mi W, Belyavskyi M, Johnson RR, Sieve AN, Storts R, Meagher MW, Welsh CJR: Alterations in chemokine expression following Theiler's virus infection and restraint stress. J Neuroimmunol 2004;151:103-115.
50 Steelman AJ, Dean DD, Young CR, Smith R, Prentice TW, Meagher MW, Welsh CJR: Restraint stress modulates virus specific adaptive immunity during acute Theiler's virus infection. Brain Behav Immun 2009;23:830843.

51 Brahic M, Stroop WG, Baringer JR: Theiler's virus persists in glial cells during demyelinating disease. Cell 1981;26:123-128.

52 Rodriguez M, Pavelko K, Coffman RL: Gamma interferon is critical for resistance to Theiler's virus-induced demyelination. J Virol 1995;69:7286-7290.

53 Feng N, Pagniano R, Tovar CA, Bonneau RH, Sheridan JF, Glaser R, Moynihan JA: The effect of restraint stress on the kinetics, magnitude, and isotype of the humoral immune response to influenza virus infection. Brain Behav Immun 1991;38:129-137.

54 Sapatino BV, Petrescu A, Rosenbaum B, Piedrahita J, Smith R, Welsh CJR: Characteristics of cloned cerebrovascular endothelial cells following infection with Theiler's virus. II. Persistent infection. J Neuroimmunol 1995;62:127-135.

55 Steiner CM, Rozhon EJ, Lipton HL: Relationship between host age and persistence of Theiler's virus in the central nervous system of mice. Infect Immun 1984;43:432-434.

56 McEwen BS: Physiology and neurobiology of stress and adaptation: central role of the brain. Physiol Rev 2007;87:873-904.

57 Harizi H, Homo-Delarche F, Amrani A, Coulaud J, Mormède P: Marked genetic differences in the regulation of blood glucose under immune and restraint stress in mice reveal a wide range of corticosensitivity. J Neuroimmunol 2007;189:59-68.

58 Shanks N, Griffiths J, Zalcman S, Zacharko $\mathrm{RM}$, Anisman $\mathrm{H}$ : Mouse strain differences in plasma corticosterone following uncontrollable footshock. Pharmacol Biochem Behav 1990;36:515-519.

59 de Jong IEM, Oitzl MS, Kloet ER: Adrenalectomy prevents behavioural sensitisation of mice to cocaine in a genotype-dependent manner. Behav Brain Res 2007;177:329-339.

60 Oleszak EL, Chang JR, Friedman H, Katsetos $\mathrm{CD}$, Platsoucas CD: Theiler's virus infection: a model for multiple sclerosis. Clin Microbiol Rev 2004;17:174-207.

61 Charcot JM: Lectures on diseases on the nervous system (transl by Sigerson G). London, New Sydenham Society, 1877.

62 Nisipeanu P, Korczyn AD: Psychological stress as risk factor for exacerbations in multiple sclerosis. Neurology 1993;43:13111312. 